\title{
Influence of Stirring Speed on Microstructure and Wear Morphology of $\mathrm{SiC}_{\mathrm{p}}-6061 \mathrm{Al}$ Composite
}

\author{
Adetayo Abdulmumin Adebisi, Md Abdul Maleque, and Mohammed Baba Ndaliman
}

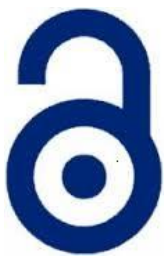

Received: 15 September 2016

Accepted: 26 September 2016

Published: 01 October 2016

Publisher: Deer Hill Publications

(c) 2016 The Author(s)

Creative Commons: CC BY 4.0

\begin{abstract}
The aim of this study is to investigate the influence of stirring speed on stir casting synthesis of $15 \mathrm{wt} \%$ silicon carbide particle reinforced aluminium alloy $\left(\mathrm{SiC}_{\mathrm{p}}-6061 \mathrm{Al}\right)$ composite. The composite samples were produced at different stirring speed of 300,500 and $700 \mathrm{rpm}$. However, the processing temperature and time are maintained at $800{ }^{\circ} \mathrm{C}$ and 180 secs processing condition. Dry reciprocating wear test is conducted using a ball on disc wear tester at a constant operating condition of $50 \mathrm{~N}$ load, $10 \mathrm{~Hz}$ frequency for 30 mins on the samples. The influence of stirring speed on the microstructure and wear morphology is examined using scanning electron microscope (SEM). The result reveals that the stirring speed influenced the processing condition including the microstructure and wear topography. Composite processed at $500 \mathrm{rpm}$ attained homogeneity of the $\mathrm{SiC}_{\mathrm{p}}$ phase as observed from the microstructure. The worn surface experiences a relatively smooth mild wear without formation of cracks, porosity and craters. However, at $300 \mathrm{rpm}$ the composite experiences micro cracks with formation of abrasive grooves due to insufficient distribution of the $\mathrm{SiC}_{\mathrm{p}}$ phase. Moreover, at $700 \mathrm{rpm}$ high speed vortex formation is observed due to vigorous stirring which entraps gases and develops into large porosity, cracks and deep craters. This study establishes that stirring speed has a significant effect on the processing condition as well as the wear morphology of $\mathrm{SiC}_{\mathrm{p}}-\mathrm{Al} 6061$ composite developed using stir casting technique.
\end{abstract}

Keywords: Stir casting, Stirring speed, Wear morphology, $\mathrm{SiC}_{\mathrm{p}}-6061 \mathrm{Al}$ composite, Microstructure

\section{INTRODUCTION}

Silicon carbide particles reinforced aluminium alloy $\left(\mathrm{SiC}_{\mathrm{p}}-6061 \mathrm{Al}\right)$ composite is the most commonly used metal matrix composite due to its strength and stiffness, improved wear resistance and cost effective process technique [1]. These features makes them to emerge as an important category of materials that have potentials for structural applications in the automotive and aerospace industry. The processing of this attractive material plays a major role in determining the performance properties under operational condition [2,3]. Among the variety of processing technique, the stir casting is generally accepted and commercially viable in developing the aluminium silicon carbide composite [4]. Moreover, the properties of $\mathrm{SiC}_{\mathrm{p}}-6061 \mathrm{Al}$ composites produced by stir casting depend on process parameters such as stirring speed. For instance, the homogenous distribution of reinforcement particulate is mostly dependent on the stirring speed of the composite melt. Uniform distribution is desired in order to maximize the composite properties. In achieving these properties, the stirring speed is of utmost concern.

Several casting defects are obviously related to the extent and method in which the stirring occurred. Studies [2, 4] have shown that porosity formation is attributed to gas entrapment during vigorous stirring leading to air bubbles in the slurry either independently or as air envelopes the reinforced particles. Very high stirring speed forms a vortex on the composite melt surface. The vortex mechanism is necessary in enveloping the particles into the matrix melt as the pressure difference between the inner and the outer surface of the melt sucks the particles into the melt [5]. However, vortex formation also traps inclusions which in turn develop into porosity formation. Therefore, the vortex process system needs to be properly controlled with the appropriate stirring speed.

Naher et al., [6] studied the effect of different stirring speed on homogenous distribution of particle in fluids by simulation analysis. Experiments were examined on fluids with the same properties of liquid and semisolid aluminium condition. The use of fluid with viscosity similar to reinforced $\mathrm{Si}_{\mathrm{p}}$ aluminium composite was used in the simulation of the mixtures with various stirring speed. It is concluded from the study that stirring speed has a significant effect

A. A. Adebisi ${ }^{\circledR}$, M. A. Maleque ${ }^{1}$ and M. B. Ndaliman ${ }^{2,3}$

'Department of Manufacturing and Materials Engineering, International Islamic University Malaysia. 2 Scientific Equipment Development Institute (SEDI), Minna, Niger State Nigeria.

${ }^{3}$ Department of Mechanical Engineering, Federal University of Technology Minna, Niger State Nigeria.

冈E-mail: debisi1@yahoo.com 
on particle distribution. Moreover, Prabu et al., [7] also investigated the effects of stirring speed on uniform distribution of $\mathrm{SiC}_{\mathrm{p}}$ in $\mathrm{Al}$ alloy matrix. This investigation considered the effect on the hardness value and microstructure. It was revealed that at higher stirring speed the porosity is observed to be more pronounced in the microstructure due to the vigorous stirring which enables oxide skins, gases and contaminations entrapped in the melt. Also, the hardness test indicates regions of both high and low value at lower stirring speed due to particle accumulation in some places and the non-inclusion of $\mathrm{SiC}_{\mathrm{p}}$ in other places. Similarly, higher stirring speed shows a non-uniform hardness value. This non uniformity is generated due to porosity, oxide skins, and formation of gases. Therefore, an optimum stirring speed is required in order to achieve uniform distribution in the matrix to attain uniform hardness.

Based on the studies highlighted, the stirring speed is recognised as an important process parameter for processing aluminium composite. Though, there is no information available in the literature on the effect of this parameter on wear performance. Therefore, this study aims to investigate the influence of stirring speed on wear morphology of $\mathrm{SiC}_{\mathrm{p}}-\mathrm{Al}$ composite using the stir casting process.

\section{METHODOLOGY}

2.1 Material Preparation

AA6061 aluminium alloy is used as the matrix material and silicon carbide particles $\left(\mathrm{SiC}_{\mathrm{p}}\right)$ as the reinforcement phase material with an average size of $40 \mu \mathrm{m}$. Table 1 shows the properties of the matrix and reinforcement materials.

Table 1. Properties of matrix (AA6061) and reinforcing $\left(\mathrm{SiC}_{\mathrm{p}}\right)$ phase.

\begin{tabular}{lccc}
\hline Property & Unit & $\mathrm{Al}(6061)$ & $\mathrm{SiC}_{\mathrm{p}}$ \\
\hline Density & $\mathrm{g} / \mathrm{cm}^{3}$ & 2.7 & 3.22 \\
Melting point & ${ }^{\circ} \mathrm{C}$ & 660 & 2973 \\
Coefficient of thermal expansion & $\mu \mathrm{m} / \mathrm{m}^{\circ} \mathrm{C}$ & 23.4 & 4 \\
Thermal conductivity & $\mathrm{W} / \mathrm{mK}$ & 166 & 126 \\
Young's modulus & $\mathrm{GPa}$ & 70 & 410 \\
\hline
\end{tabular}

\subsection{Composite Processing Procedure}

The composite was developed using an electric resistance induction stir casting set up incorporated with a preheating furnace, vacuum chamber, stainless steel stirrer and attached die cavity. The melting furnace for Al alloy matrix has a heating capacity of $1000^{\circ} \mathrm{C}$ while the reinforcement $\left(\mathrm{SiC}_{\mathrm{p}}\right)$ heating can be heated to $1200{ }^{\circ} \mathrm{C}$. The temperature value is determined with a $\mathrm{K}$ - type thermocouple for sensing the temperature during the melting process until the desired temperature is attained on the indicator. The $\mathrm{SiC}_{\mathrm{p}}$ powder is preheated to $1100^{\circ} \mathrm{C}$ for $2 \mathrm{hrs}$ in order to initiate surface oxidation before incorporating into the aluminium melt [8].

After melting of the aluminium alloy, dross formation is extracted from the melt surface with a coated skimmer which has been preheated. Moreover, before the addition of $\mathrm{SiC}_{\mathrm{p}}, 1 \mathrm{wt} \%$ magnesium was incorporated in the aluminium melt to improve the wettability between the matrix and reinforcement phase. Subsequently, the injection of $\mathrm{SiC}_{\mathrm{p}}$ was slowly added to the aluminium melt within an average of one (1) min as the stirrer (stainless steel) is gradually lowered into the furnace in order to perform stirring and pouring. The die steel is heated to $500{ }^{\circ} \mathrm{C}$ for 1 $\mathrm{hr}$ and then positioned in a vacuum chamber of $350 \mathrm{mmHg}$ before pouring take place. Throughout this process, the composite melt is monitored to be in a molten state.

\subsection{Wear Testing}

Dry reciprocating wear test is conducted using a ball on disc high frequency reciprocating rig (HFRR) tester (as shown in Figure 1) according to ASTM D 6079-97/EN 590. The wear test is conducted at a constant operating condition of $50 \mathrm{~N}$ load, $10 \mathrm{~Hz}$ frequency for 30 mins. Each of the composite produced at different stirring speed was tested against a 52100 chrome steel material with $\varnothing 6 \mathrm{~mm}$ and $60-67 \mathrm{HRC}$ hardness value. All the cast sample were cleaned with acetone prior and after testing and weighed using a micro scale weighing balance with an accuracy of $0.0001 \mathrm{~g}$. The wear rate is determined using the weight loss method as described in equation (1):

$$
\begin{gathered}
w_{r}=\frac{\Delta m}{\rho t} \\
\Delta m=\text { mass loss, } \rho=\text { density, } t=\text { time }
\end{gathered}
$$




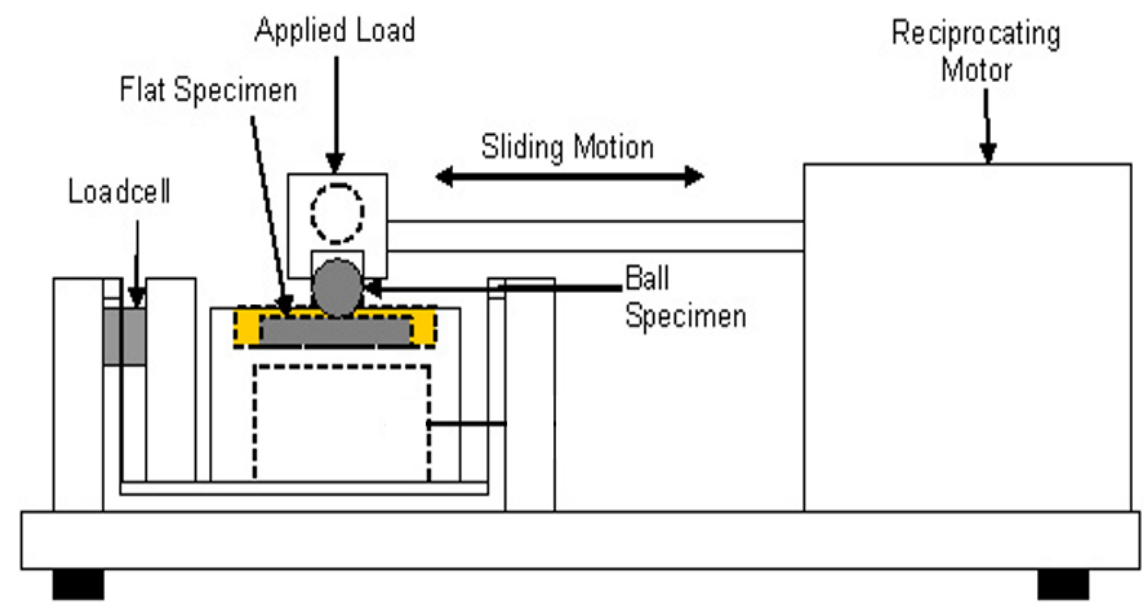

Figure 1: Schematic view of wear testing machine.

\section{RESULTS AND DISCUSSION}

\subsection{Microstructure}

Figure 2 (a) shows the scanning electron microscope (SEM) of A16061 alloy and the presence of magnesium and silicon in the $\mathrm{Al}$ alloy is confirmed from the energy dispersive $\mathrm{x}$-ray spectroscopy (EDS) analysis as shown in Figure 2(b). The morphology of the $\mathrm{SiC}_{\mathrm{p}}$ powder is shown in Figure 3(a) with the EDS analysis in Figure 3(b). The average size of the $\mathrm{SiC}_{\mathrm{p}}$ is $40 \mu \mathrm{m}$.
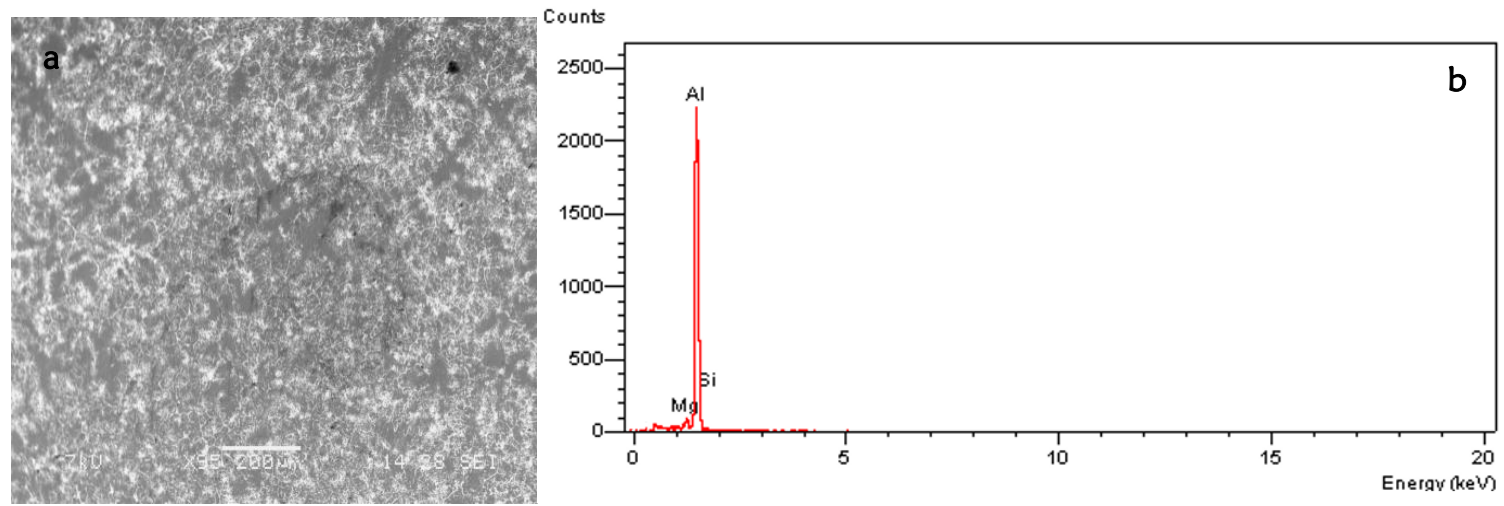

Figure 2: (a) Scanning electron micrograph (b) energy dispersive x-ray spectroscopy of 6061Al alloy.
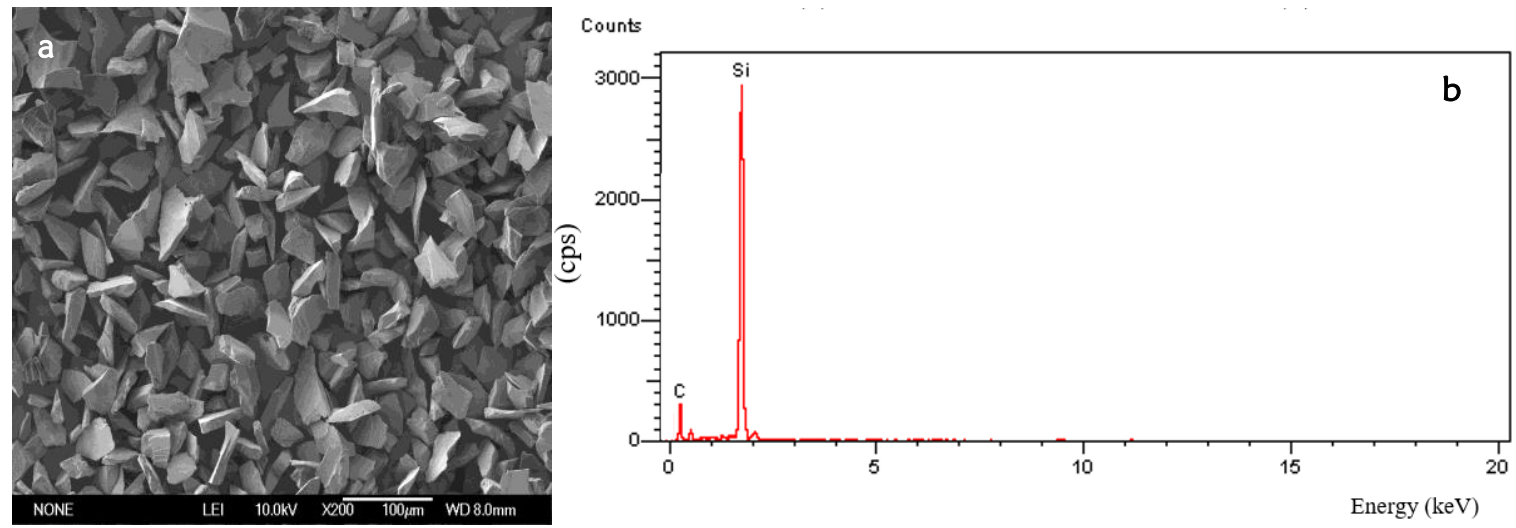

Figure 3: (a) Scanning electron micrograph (b) energy dispersive $\mathrm{x}$-ray spectroscopy of $\mathrm{SiC}_{\mathrm{p}}$. 


\subsection{Effect of Stirring Speed on the Microstructure of $\mathrm{SiC}_{\mathrm{p}}-\mathrm{Al}$ Composite}

Homogenous distribution of the $\mathrm{SiC}_{\mathrm{p}}$ is desirable in order to optimize the properties of $\mathrm{SiC}_{\mathrm{p}}-\mathrm{Al}$ composite. To achieve this, the processing condition of the stir casting technique is of utmost importance. Therefore, it is essential to examine the influence of stirring speed, a crucial parameter in stir casting, on the distribution of $\mathrm{SiC}_{\mathrm{p}}$ in $\mathrm{Al}$ alloy matrix. Samples from the cast composite processed at 300,500 and $700 \mathrm{rpm}$ were analysed through microstructure analysis. From the microstructural characterization it is observed that stirring speed significantly influenced the distribution of $\mathrm{SiC}_{\mathrm{p}}$ which is evident in Figure 4b.

At $300 \mathrm{rpm}$, it is observed from the micrograph that regions of clustering and micro porosity is detected. Moreover, the distribution of $\mathrm{SiC}_{\mathrm{p}}$ is not uniformly dispersed as viewed in Figure 4(a). This indicates that $300 \mathrm{rpm}$ is insufficient to achieve homogenous distribution of $\mathrm{SiC}_{\mathrm{p}}$ in the $\mathrm{Al}$ alloy matrix. With higher stirring speed of $500 \mathrm{rpm}$, an improved distribution of the $\mathrm{Si}_{\mathrm{p}}$ is achieved as shown in Figure 4(b) indicating the $\mathrm{Si}_{\mathrm{p}}$ is uniformly dispersed in the matrix alloy. Moreover, vortex formation is found to be minimized at $500 \mathrm{rpm}$ stirring speed thereby stabilizing centrifugation which may lead to minimal stirring efficiency and potentially severe air entrainment at higher stirring condition.

At higher stirring speed of $700 \mathrm{rpm}$, the porosity in the microstructure is more pronounced as observed from the micrograph in Figure 4(c). This condition is attributed to the vigorous vortex formation due to high stirring speed which enables oxide skins, gases and contaminants to be entrained in the melt. Furthermore, the distribution of the $\mathrm{SiC}_{\mathrm{p}}$ is not effective enough due to the formation of undesirable conditions such as large porosity and gas entrapment.

\subsection{Effect of Stirring Speed on Wear Morphology of $\mathrm{SiC}_{\mathrm{p}}-\mathrm{Al}$ Composite}

Dry reciprocating wear test is conducted on the $\mathrm{Si}_{\mathrm{p}}-\mathrm{Al}$ composite processed at different stirring speed of 300, 500 and $700 \mathrm{rpm}$. The surface wear morphology of these composites were evaluated based on the wear test condition of $50 \mathrm{~N}$ load, $10 \mathrm{~Hz}$ frequency for 30 mins. Figure 5 shows the wear morphology of $\mathrm{SiC}_{\mathrm{p}}-\mathrm{Al}$ composites considering the influence of stirring speed condition. Figure 5(a) examines the composite processed at $300 \mathrm{rpm}$. It is observed that the surface topography is characterized by both abrasive and adhesive wear mechanism as indicated with regions of groove formation and regions of particle clustering compaction respectively. Moreover, due to the insufficient distribution of the reinforced $\mathrm{SiC}_{\mathrm{p}}$, the surface is characterised with micro cracks and regions of densely packed $\mathrm{SiC}_{\mathrm{p}}$. As such abrasive grooves are observed in areas where the $\mathrm{SiC}_{\mathrm{p}}$ is absent which eventually formed abrasive grooves as shown in 5(a).
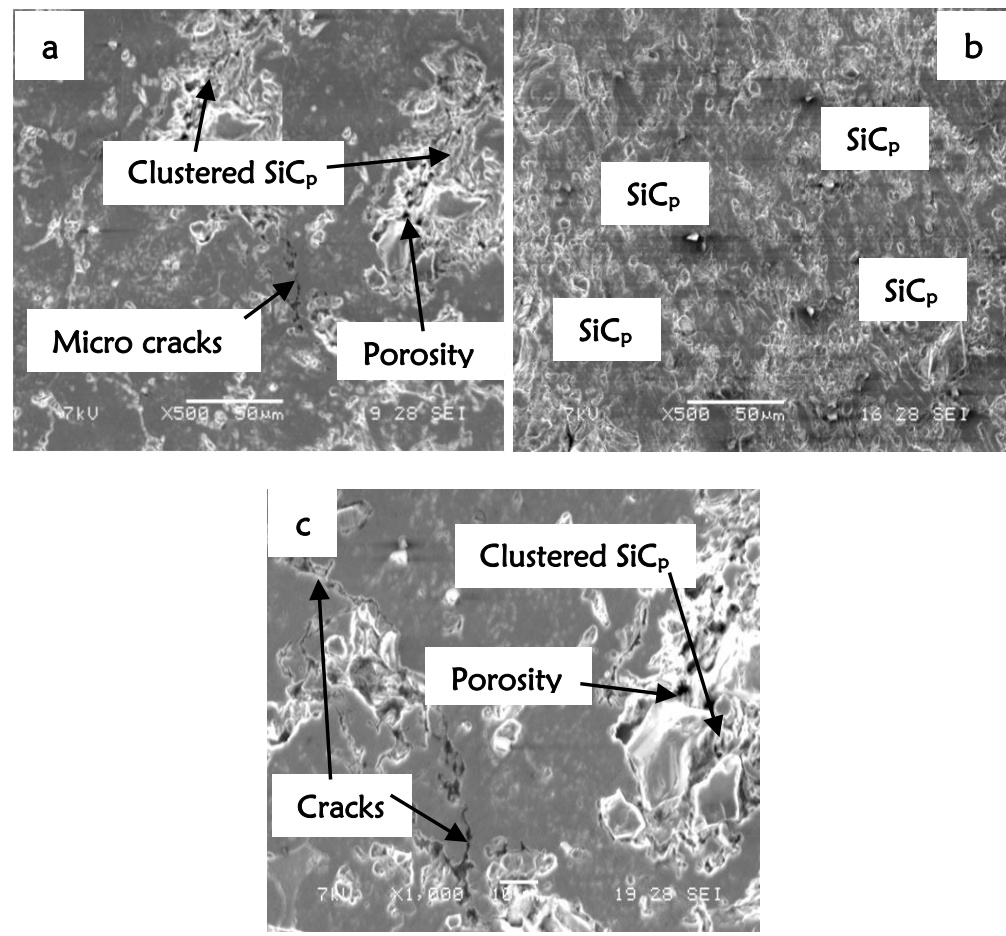

Figure 4: Microstructure of $15 \mathrm{wt} \% \mathrm{SiCp} \mathrm{Al} \mathrm{composite} \mathrm{processed} \mathrm{at} \mathrm{(a)} 300 \mathrm{rpm}$ (b) $500 \mathrm{rpm}$ and (c) $700 \mathrm{rpm}$. The formation of composites, porosity, and micro cracks are indicated. 

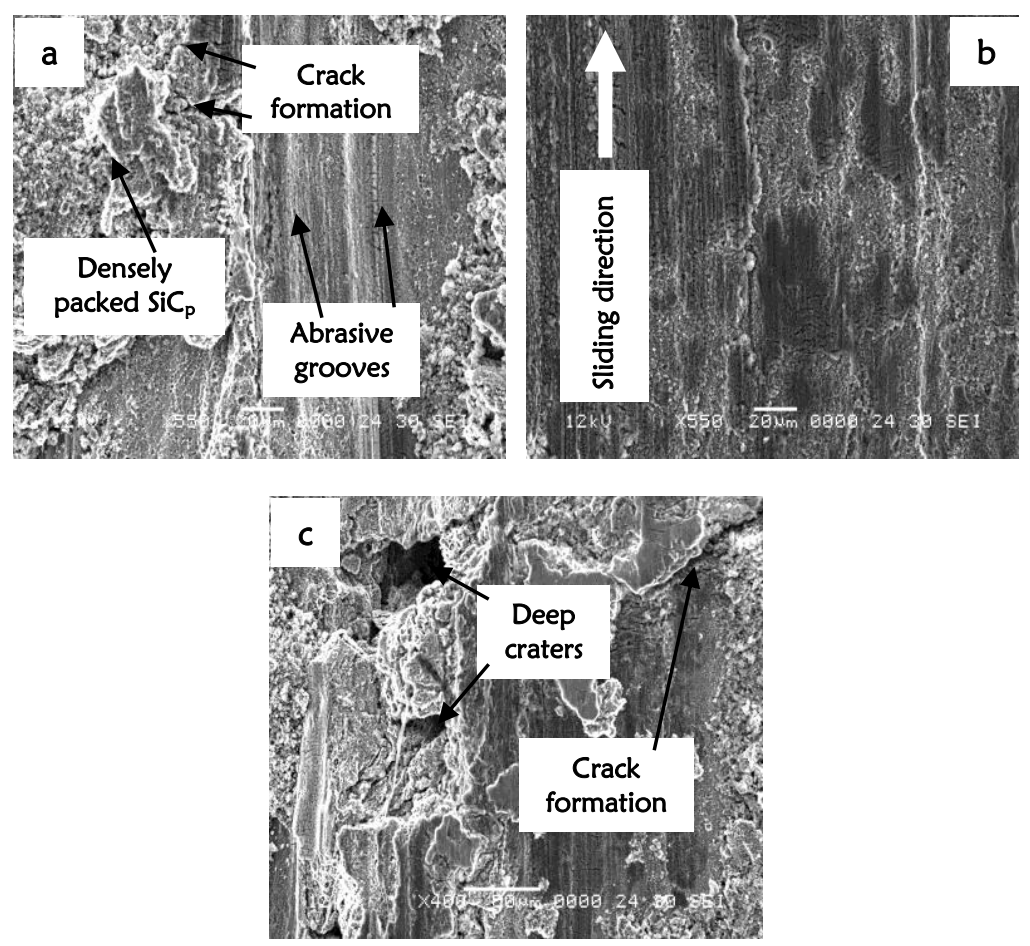

Figure 5: Wear morphology of $15 \mathrm{wt} \% \mathrm{SiC}_{\mathrm{p}} \mathrm{Al}$ composite processed at (a) $300 \mathrm{rpm}$ (b) $500 \mathrm{rpm}$ and (c) $700 \mathrm{rpm}$. The formation of craters, cracks, and abrasive grooves are indicated.

However, composite processed at $500 \mathrm{rpm}$ shows that the topography of the worn surface is characterised with a relatively smooth mild wear without formation of cracks and porosity as shown in Figure $5(b)$. This is attributed to the uniform distribution of the $\mathrm{SiC}_{\mathrm{p}}$ attained with $500 \mathrm{rpm}$ stirring speed and also the sufficient wettability between the reinforcement and $\mathrm{Al}$ alloy. This provides adequate rubbing and stable contact between the composite and the counter surface during the wear test. The stable interaction results to the formation of oxide layer on the wear surface which is viewed as the whitish scale profile on the SEM micrograph. This layer serves as a protective surface which improves the abrasion and adhesion resistance of the composite.

Figure 5(c) describes the wear topography of composite processed at $700 \mathrm{rpm}$, the surface is characterized with numerous deep craters with crack formation due to the vigorous stirring speed used in the processing. This condition is ascribed to the high speed vortex formation which entraps inclusions such as gases which in turn develops into large porosity formation.

\section{CONCLUSIONS}

The influence of stirring speed on the microstructural and wear morphology of $15 \mathrm{wt} \% \mathrm{SiC}-\mathrm{Al}$ composite was studied. It was found that the stirring speed has significant influence on the properties of composite. The following conclusions were drawn from the experimental results:

1. The $\mathrm{SiC}_{\mathrm{p}}-\mathrm{Al}$ composite was successfully processed and developed using the stir casting technique by varying the stirring speed.

2. The composite achieved uniform particle distribution with $500 \mathrm{rpm}$ stirring speed which in turn translates to improved microstructural and wear properties.

3. From the microstructural analysis, it is found that at $300 \mathrm{rpm}$ stirring speed, the composite experiences micro cracks with formation of abrasive grooves due to insufficient distribution of the $\mathrm{SiC}_{\mathrm{p}}$ phase. Moreover, at 700 rpm high speed vortex formation is observed due to vigorous stirring which entraps gases and develops into large porosity, cracks and deep craters.

4. The wear morphology of the composite processed at $500 \mathrm{rpm}$ shows that the topography of the worn surface is characterised with a relatively smooth mild wear without formation of cracks and porosity. This feature is attributed to the uniform distribution of the $\mathrm{SiC}_{\mathrm{p}}$ in the matrix and also the sufficient wettability achieved between the reinforcement and $\mathrm{Al}$ alloy. 
5. The surface topography of the composite processed at 300 and $700 \mathrm{rpm}$ is characterized with the formation of abrasive grooves, micro cracks and development of large porosity (deep craters) with cracks respectively.

6. Achieving optimum stirring speed of $500 \mathrm{rpm}$ during the processing of $\mathrm{SiC}_{\mathrm{p}}-\mathrm{Al}$ composite improves and also maximise the microstructural and wear properties.

\section{ACKNOWLEDGEMENT}

The authors acknowledge the support of the Ministry of Education and International Islamic University Malaysia (IIUM) for the financial support to conduct this research under research project PRCS12-002-0002. The authors also appreciates the Foundry Workshop and Metallographic Laboratory at IIUM where the experimental studies were conducted.

\section{REFERENCES}

1. Evans, A., San Marchi, C., \& Mortensen, A. (2013). Metal matrix composites in industry: an introduction and a survey. New York: Springer Science \& Business Media.

2. Sozhamannan, G., Prabu, S. B., \& Venkatagalapathy, V. (2012). Effect of processing parameters on metal matrix composites: stir casting process. Journal of Surface Engineered Materials and Advanced Technology, 2(1), 11-15.

3. Adebisi, A. A., Maleque, M. A. \& Shah, Q. H. (2014). Performance assessment of aluminium composite material for automotive brake rotor. International Journal of Vehicle Systems Modelling and Testing, 9(3-4), 207-217.

4. Bharat, K., \& Jyoti, V. M. (2016). Aluminium-based metal matrix composites by stir casting: a literature review. International Journal of Materials Engineering Innovation, 7(1), 1-14.

5. Ahmad, S. N., Hashim, J. \& Ghazali, M. I. (2005). The effects of porosity on mechanical properties of cast discontinuous reinforced metal matrix composite. Journal of Composite Materials, 39, 451-466.

6. Naher, S., Brabazon, D., \& Looney, L. (2003). Simulation of the stir casting process. Journal of Materials Processing Technology, 143, 567-571.

7. Prabu, S. B., Karunamoorthy, L., Kathiresan, S., \& Mohan, B. (2006). Influence of stirring speed and stirring time on distribution of particles in cast metal matrix composite. Journal of Materials Processing Technology, 171(2), 268-273.

8. Adebisi, A. A., Maleque, M. A., Ali, M. Y. \& Bello, K. A. (2016). Effect of variable particle size reinforcement on mechanical and wear properties of 6061AI-SiC composite. Composite Interfaces, 23(6), 533-547. 